\title{
Adopting process-relational perspectives to tackle the challenges of social- ecological systems research
}

\author{
María Mancilla García $^{1}$, Tilman Hertz $^{1}, \underline{\text { Maja Schlüter }}^{1}$, Rika Preiser $^{2}$ and Minka Woermann $^{3}$
}

\begin{abstract}
Despite many recent advances in sustainability science, researchers still struggle to address the key characteristics of social-ecological systems that underlie many of today's problems. Complex cross-scale dynamics and tightly interrelated social and ecological processes characterize social-ecological systems (SES). These features lead to constant change and novelty. Process philosophers argue that the difficulties of capturing these features may have their roots in our tendency to understand the world in terms of substances. This tendency is a legacy of dominant philosophical views that, although now debunked, continue to inform (albeit mostly implicitly) our explanations of reality. These philosophical views are based on the primacy of fundamental entities and stability, which is in contradiction to the continuously changing nature of SES. In this paper, we demonstrate that adopting a processrelational perspective, which focuses on nonequilibrium dynamics and relations between processes, provides novel opportunities to advance SES research. We propose concrete steps toward developing a process-relational perspective of SES and discuss how such a perspective can help us to overcome the challenges currently facing SES research.
\end{abstract}

Key Words: complexity; continuous change; paradigm shift; process-relational; social-ecological intertwinedness

\section{INTRODUCTION}

Social-ecological systems (SES) research has developed as a field of interdisciplinary sustainability science (Schoon and van der Leeuw 2015). It views environmental problems as intertwined phenomena that are produced by the dynamic interactions of diverse social actors and ecological elements across multiple scales (Olsson and Folke 2001, Levin et al. 2013). Although the complex and intertwined nature of social-ecological systems is now widely accepted (Preiser et al. 2018, Schlüter et al. 2019), recent assessments of the field indicate that it remains a challenge to fully account for these entanglements (Fischer et al. 2015, Turner et al. 2016, Kramer et al. 2017, Guerrero et al. 2018). Current approaches are limited when it comes to addressing the interdependence between the social and ecological, beyond showing how one system drives or constrains the other. In this paper, we propose a shift toward a process-relational perspective, and explore how it may provide opportunities for overcoming key challenges of SES research.

SES researchers rarely reflect on the ontology of the systems that they work with. However, a critical reflection on ontology may be essential for addressing the challenges of the complex and intertwined nature of social-ecological systems (Stone-Jovicich 2015). Such a reflection seeks to define the constituents of the nature of reality and an explanation for their properties. This is a different task to developing new theories, which seeks to explain specific phenomena through confirming or rejecting hypotheses. A reflection on ontology instead revises the meaning of the concepts that we employ to develop theories, thereby opening up possibilities to propose new concepts and imagine other avenues of analysis. A process-relational perspective provides conceptual constructs that highlight connections and relational qualities, such as the concept of process itself. By using concepts that both bridge the dichotomy of the social and the ecological and focus on dynamical modes of interaction, a process-relational perspective may help develop a conception of social-ecological systems as integrative and ever-evolving.

A process-relational perspective focuses attention on processes, as opposed to objects, as the primary constituents of reality. Processes can be understood as patterns and their properties and functions are defined by the set of relations that constitute them. These relations span over different realms, such as the social and the ecological, which is why a process-relational perspective is particularly useful for reflecting on the ontology of socialecological systems. Additionally, a process-relational perspective can help to integrate complex adaptive systems theory or complexity theory in the study of SES (Rogers et al. 2013). For example, processes allow us to think in terms of emergent phenomena that can be more or less stable over time, a key feature of complex adaptive systems. The processes that are capable of actualizing depend on unfolding events. These unfolding events recursively create new events, which are initiated by the set of possible, evolving relations that can be actualized (Arthur 2009). The notion of emergent events is well explained by Arthur (2009), who clarifies how structural changes in the economy are the result of the recursive effects of introducing new technologies. He argues that "structural change in the economy is not just the addition of a novel technology and replacement of the old, and the economic adjustments that follow these. It is a chain of consequences where the arrangements that form the skeletal structure of the economy continually call forth new arrangements" (Arthur 2009:198). The introduction of the factory, for example, did not just change how society produced products in a mechanical manner, but "created a new set of organizational arrangements" that "called for a new kind of person"-the factory worker-and even caused "psychological change" (Arthur 2009:198). As such, the economy is an emergent feature of the process-relational nature of

\footnotetext{
${ }^{1}$ Stockholm Resilience Centre, Stockholm University, Sweden, ${ }^{2}$ Centre for Complex Systems in Transition, Stellenbosch University, South Africa,
} ${ }^{3}$ Department of Philosophy, Stellenbosch University, South Africa 
technology, and it emerges as "a set of arrangements that forms the processes, organizations, devices and institutional provisions that comprise the evolving collective" (Arthur 2009:199).

Process-relational perspectives have a long history in philosophy. The Greek philosopher Heraclitus (approx. 500 BC), to whom the phrase "everything flows" is attributed, originally proposed a focus on processes and relations as the fundamental constituents of reality. However, modern science, including many of the scientific disciplines that contribute to sustainability science, largely but often implicitly accepts, and works with, standard scientific perspectives that have their roots in the thinking of philosophers such as Plato, Aristotle, or Descartes (May 2005). These philosophers endorse substance perspectives, that is, perspectives that give existential priority to objects and present change as secondary and exceptional. This seems in stark contrast to the ever-changing nature of SES. In a substance perspective, objects are defined in terms of well-defined properties (their "substance"), which are viewed as more fundamental than processes and relations. As a result, substance perspectives enforce the separation between the social and ecological spheres, thereby limiting the scope of their integration.

Consider for example, the standard approaches to conceptualizing the relations between the social and the ecological domains in sustainability discourse at large. These approaches range on a continuum from strong anthropocentricism, which includes the relational modes of detachment, domination, and utilization, to deep ecology, which supports the relational mode of wardship (Muradian and Pascual 2018). However, despite the ideological differences between these positions, they share the ontological commitment that nature exists as a separate material realm, and that nature lacks agency. Deep ecology thus remains tethered to (and limited by) the same substance ontology informing anthropocentrism, and therefore cannot offer a radical alternative to anthropocentrism. In contrast, we argue that a shift to process ontology can help us to theorize the social and ecological dimensions in novel ways.

Of late, there has been a renewed interest in process-relational perspectives inspired by the seminal work of Alfred North Whitehead, and, to a lesser extent, the works of Henri Bergson, C. S. Peirce, William James, and Gilles Deleuze (Ivakhiv 2018). Processes and relations are typically viewed as synonymous in philosophy, and this conceptual conflation has carried over into other disciplines (Mesle 2008). However, there is also an emerging body of research that views processes and relations as different, and as belonging to different traditions (Garud et al. 2015). SES research specifically has recently witnessed a boom of works on "relationality," including relational values and relational approaches (Cooke et al. 2016, West et al. 2018). In contrast, the concept of process has received less attention in this field. In this paper, we shall employ the term "process" when emphasizing dynamics, and the term "relations" when emphasizing linkages. Yet, because this paper invites a reflection on ontology, we follow the philosophical tradition that tends to see processes and relations as two sides of the same coin (Ivakhiv 2018). When thinking in terms of complex adaptive systems, the properties and functions of processes are defined by verbs (Arthur 2015), as opposed to nouns, and these properties and functions inform our understanding of the qualities and effects of the relations that constitute nonequilibrium systems.
One key difference between the process-relational approach put forward in this paper and other current ontological perspectives for understanding SES (including critical realism), is that processrelational perspectives do not enforce a separation between epistemology and ontology. This means that processes and relations do not have an existence independent of an observer. However, this does not mean that the process-relational account is a subjectivist account (see Duvernoy's 2016 discussion of Deleuze's perspectivism), which would again suppose a difference between the observer and the observed.

Forefronting processes and relations in a research perspective leads to a focus on change, which is viewed as a core characteristic of complex adaptive systems rather than an exceptional state (Arthur 2015). Furthermore, and as previously stated, in focusing on processes and relations, instead of entities, the conceptual separation between the social and the ecological is also challenged. Many disciplines contributing to SES research have developed in a manner that enforces the bifurcation of nature and society, which process-relational perspectives attempt to overcome. The concepts that we propose are certainly not free from disciplinary influences because they stem from specific perspectives in philosophy and related disciplines. Yet, the perspectives that we draw on actively seek to overcome the bifurcation of nature and society, and are hence free from the associated problems that such a bifurcation introduces.

In this paper, we explore the value and potential of a processrelational perspective in order to pave the way for a fully integrative approach that overcomes the dichotomy between social and ecological and that does justice to the ever-changing nature of SES. We do so by reviewing key challenges recently put forward for SES research, and discuss how a process-relational perspective, together with critical reflections on the ontological commitment of SES research, may help to address these challenges.

\section{CHALLENGES OF SOCIAL-ECOLOGICAL SYSTEM (SES) RESEARCH}

Several recent reviews of the state of SES research acknowledge its significant achievements, including a growing recognition that humanity depends on nature, an increase in collaboration and cooperation among disciplines (also beyond the scientific domain), and a growing influence of SES perspectives on major policy frameworks (Fischer et al. 2015, Turner et al. 2016, Kramer et al. 2017, Guerrero et al. 2018). These studies, however, also point to major remaining challenges, of which the four most prevalent are (i) integrating the social and ecological, (ii) better accounting for complexity, (iii) better accounting for dynamics across scales (time and geographical), and (iv) better combining/ integrating different knowledge systems (see Table 1).

To identify recent reviews of the state of SES research we conducted a literature search on Web of Science. Search terms included "state of the art," "reviews," "syntheses," "future challenges," "future research," all in conjunction to the search term "social-ecological systems." The findings were ordered by date to account for the most recent thinking in the field, considering 2015 the oldest date. Only articles that spoke about challenges of the field (not a specific methodology) were selected, which gave a total of four articles. However, an overview of the extant literature attests to the fact that these challenges are currently dominating the discussion in SES research. Not all of 
Table 1. Overview of the challenges and supporting statements. CHANS, coupled human and natural systems.

\begin{tabular}{l}
\hline \hline Challenge \\
\hline Integrating the social and the ecological \\
"An integrated understanding of both social and ecological aspects of environmental issues is essential to address pressing sustainability \\
challenges ... We conducted a systematic literature review to investigate the conceptual, methodological, disciplinary, and functional aspects \\
of social-ecological integration. In general, we found that overall integration is still lacking in social-ecological research." (Guerrero et al. \\
2018) \\
"People and nature are inextricably linked. Overcoming pressing sustainability challenges thus requires an integrated social-ecological \\
science." (Guerrero et al. 2018, referring to Liu et al. 2007) \\
"How can we reintegrate humans into our conceptualization and management of "natural" systems?" (Kramer et al. 2017) \\
"How can we better represent social systems and processes in CHANS models?" (Kramer et al. 2017) \\
"The crucial role that social-ecological linkages play in the pursuit of sustainability is increasingly being recognized. Yet, the consequences of
\end{tabular}
this recognition still need to be embraced much more broadly and deeply by society." (Fischer et al. 2015:146)

Understanding complex interactions and dynamics

"Accounting for Change. Social-environmental systems typically change rapidly, often in unpredictable ways due to the complexity of the systems in question." (Turner et al. 2016:165 [emphasis in the original])

"How can we understand causation in complex coupled systems?" (Kramer et al. 2017)

"How can we incorporate behavior, tipping points, emergent properties, and regime shifts, especially for ecosystem function and social organizations, in CHANS models?” (Kramer et al. 2017)

"Overcoming prominent conservation and development challenges requires an understanding of the complex and evolving links between ecosystems and human societies.” (Fischer et al. 2015:144)

"In the face of increasingly ... rapid and interconnected social and ecological change, we argue that a step-change is needed in how research is done and how research and society relate to each other." (Fischer et al. 2015:147)

"Issues related to power and justice are important in their own right, and also can have a decisive impact on whether efforts to improve ecological outcomes succeed or fail." (Fischer et al. 2015:147)

Addressing issues of scale

"How can scientists best integrate data, methods, and research designs across multiple spatial and temporal scales?" (Kramer et al. 2017)

"What are the social drivers at multiple scales of complex CHANS?" (Kramer et al. 2017)

"Although rapid changes can be very important in some settings, it is widely acknowledged that slow drivers can exert disproportionate control on the long-term trajectory of social-ecological systems, ... Slow drivers, however, cannot be easily studied.” (Fischer et al. 2015:147)

"In the face of increasingly large-scale ... social and ecological change, we argue that a step-change is needed in how research is done and how research and society relate to each other." (Fischer et al. 2015:147)

Integrating different knowledge systems

"Nevertheless, the level of coordination and integration between the natural and the social sciences commonly remains inadequate." (Turner et al. 2016:166)

"Although the concept of social-ecological systems has gained currency in the last few years, many researchers active in this area still face incentive structures that primarily reward disciplinary science that does not engage with society." (Fischer et al. 2015:147-148)

"How can we ensure that interdisciplinary projects that include nonacademic stakeholders become the norm rather than the exception (especially in sustainability science)?” (Kramer et al. 2017)

the challenges documented in Table 1 are mentioned in all papers reviewed, and some papers also mention other challenges (especially Turner et al. 2016 and Kramer et al. 2017).

\section{ADDRESSING THE CHALLENGES FROM A PROCESS PERSPECTIVE}

\section{Integrating the social and the ecological}

Although the need to conceptualize and study SES as truly integrated systems has long been recognized and lies at the core of our understanding of SES, developing appropriate frameworks and conceptual tools to achieve this integration has proven challenging (Fischer et al. 2015, Kramer et al. 2017, Guerrero et al. 2018). The state-of-the-art reviews documented in Table 1 highlight the necessity for more in-depth studies of the "links" (Fisher et al. 2015, Guerrero et al. 2018) or relations between the social and the ecological, as well as the "processes" (Kramer et al. 2017) that bring them together. A process-relational perspective could be helpful here precisely because it focuses attention on the links and processes. 
Indeed, numerous calls for process-relational perspectives in SES research have arisen in recent years (as attested to by the December 2018 Special Issue, "Sustainability Challenges: Relational Values" in Current Opinion in Sustainability Science). Processrelational approaches are currently also advocated in other fields, such as biology (Nicholson and Dupré 2018), complex systems studies (Weinbaum 2015), complexity economics (Arthur 2015), and human geography (Stark 2017). SES scholarship that contains (or highlights the need for) elements of processrelational thinking in SES research include works on embedded cognition (Giusti 2018), the theory of practice (West 2016), and certain developments around social-ecological networks (Alonso Roldán et al. 2015) and agent-based modeling (e.g., Lindkvist et al. 2017). Cooke et al. (2016) provide a very interesting example of using a relational approach to redefine important concepts of resilience thinking, such as planetary boundaries and reconnecting to the biosphere.

From a process-relational perspective, the social and the ecological are not two realms that exist separately and interact with each other in a secondary fashion. Rather, the socialecological is a priori constituted through processes. The social and the ecological only exist through virtue of the interactions between them, and can thus only be understood ontologically with respect to each other. In this view of reality, relations have causal agency and stand prior to objects, whose identities are formed by relations. This means that a process-relational perspective will focus on the past and present processes and relations that constitute, are constituted by, and bring about changes in, a system. This understanding of reality requires that we reconceptualize the underlying assumptions defining the social-ecological construct, specifically the implicit bifurcation of nature and society.

\section{Understanding complex interactions and dynamics}

For the past few decades, researchers in sustainability science have called attention to the importance of considering the complexity and nonlinear dynamics of SES, such as the networks of interactions between SES elements or feedbacks that influence systems' behavior (Cilliers 2008, Wells 2013, Peter and Swilling 2014). SES have been defined as complex adaptive systems (Preiser et al. 2018, Schlüter et al. 2019), which emphasizes their continuously evolving character. In complex adaptive systems, the systemic elements continuously adapt to the changing environment that they themselves create through their interactions (Levin et al. 2013). This dynamism is fundamental to understanding systems' behavior. Thus, what we call systems and their environments are mere conceptual demarcations of sets of relations that affect one another (Rajagopalan and Midgley 2015).

From a process-relational perspective, we can define complexity as the product of causal interactions between sets of stabilized relational forms. Adopting a complexity perspective challenges current scientific understanding in that it demands that we unlearn the "reductive frame of reference" in which we traditionally operate (Rogers et al. 2013). In particular, Rogers et al. argue that current scientific practice is informed by an understanding of analysis as a task of simplification and isolation of components. In contrast, thinking in terms of ever-evolving dynamic phenomena is the raison d'être of a process perspective.
Processes can only be identified because they introduce change. Change is thus the normal behavior of the system. The task at hand is to identify processes that lead to change, and to identify the effects that unexpected changes have on different processes.

Current studies in sustainability research acknowledge the importance of change. However, because systems are often understood as constituted by a series of stable states, change, in turn, is thought to be produced by drivers that are exogenous to the system of interest (Bai et al. 2016). In contrast, a process perspective argues for understanding change as also being endogenous, that is, as coming from within (Santos 2015). As such, a process perspective resonates with evolutionary perspectives, which also focus on endogenous change, such as, for example, cultural change (Waring 2010, Waring et al. 2015). Research designs and methodologies should capture the endogenous nature of process, and account for the consequences of processes. One way in which to achieve this is through the use of anticipatory models. Anticipatory models include horizon scanning, historical reconstruction methods, and participatory scenario development. These tools model systemic processes with the goal of anticipating future systems' trajectories (Poli 2010).

\section{Addressing issues of scale}

During the past few years, the issues of scale and cross-scale interactions have been among the main concerns of the sustainability science community. The concept of fit, that is, whether there is an appropriate fit between socio-political scales and the ecological problem at hand, has received a lot of attention in the governance literature (Folke et al. 2007, Lebel et al. 2013, Guerrero et al. 2015, Bodin et al. 2019). Research on telecoupling has highlighted the importance of understanding how distant regions are linked biophysically, economically, or socially across scales (Liu at al. 2013, Martín-López et al. 2019). Research from the social sciences, in particular human geography, has also contributed to conceptualizing issues of scale, especially in arguing that governance scales enact specific distributions of power (Swyngedouw 2004).

Social-ecological interactions span many levels and scales, which makes it imprudent to focus only on a single scale, such as the local. What happens at the local scale will not only influence, and be influenced by, processes at this scale, but also by interactions at other scales. The logic of process is potentially useful to study cross-scale interactions because it is recursive: processes are both the product and producer of context. Processes unfold at different tempos and in different hierarchical networks, which create the contexts in which processes are constituted. Context is the product of a given possibility space, and different possibility spaces are observable at different scales. The set of processes, and their possible interactions, allow for the emergence of a possibility space. The possibility space transforms as processes actualize and change in interaction with other processes. This is because actualized processes impact on future possibility spaces by reconfiguring both the temporal cycles and spatial networks in which processes unfold. The concept of possibility space is thus useful to conceptualize cross-scale interactions that span different realms, such as the social and the ecological.

The concept of scale might seem at odds with process perspectives, as a number of process scholars have argued for "flat" ontologies (Marston et al. 2005, DeLanda 2006). However, recent research 
has called attention to the limitations of such perspectives, and has instead argued for including volume in process-relational ontology. Researchers working on ocean processes, for example, have proposed the term "wet ontology," which draws attention to problems of volume and scale (Steinberg and Peters 2015). It may be argued that the concept of scale is limiting because it implicitly suggests the existence of fixed boundaries between scales. However, we argue that "scale" is a useful concept in transitioning from substance to process ontologies, especially if the term is employed to draw attention to the porosity of boundaries. Such porosity is the consequence of processes unfolding at different rhythms and tempos, and in different spaces, while still being interlinked.

Consider, as an example, a cooperative managing a particular resource. Management can be realized by actualizing different relations, which at any given moment define the processes governing the possibility space. For instance, institutional arrangements can emerge through interactions at the local scale cooperative, an oversight body at national scale, and a potential financing scheme at the international scale. Recognizing these fluid cross-scale interactions lays the foundation for novel management capacities. However, the set of actualized processes (and hence the possibility space) can also change because of relational reconfigurations defining novel processes. For instance, novel processes that lead to the appearance of an invasive species create new properties and capacities that may necessitate new mandates for the cooperative, including new cross-scale interactions. The idea of the possibility space, as constantly reconfigured by actualized processes, allows management to capture the constantly evolving process contexts (and the crossscale interactions between these contexts).

\section{Integrating different knowledge systems}

Numerous authors (Lélé 1991, Norgaard 2002, Eigenbrode et al. 2007, Hertz and Schlüter 2015) have argued that the practice of inter- and transdisciplinary research benefits from disclosing ontological disciplinary differences. This is because our hypothesis on what exists determines how we can study it, as well as the methods and tools that are viewed as appropriate to the study. Inter- and transdisciplinary approaches often suffer problems of ontological, epistemological, and methodological incompatibilities. We argue that they do so precisely because different disciplines (implicitly) rely on different, and often incompatible, views of the nature of reality; that is, ontologies are incompatible.

A process-relational perspective can help to integrate different knowledge systems by transcending disciplinary boundaries in academia and beyond. This is because the set of concepts, presented above, span disciplinary boundaries. These disciplinary boundaries are often kept intact by the supposedly fundamental differences between the social and the ecological domains. In contrast, by focusing on process and relations, researchers from different disciplines should interrogate their conceptual tools so that disciplinary concepts that hinder integration can be set aside. The concepts of "process" and "relation" also emanate from certain traditions. However, these traditions do not support the bifurcation of nature and society, and therefore do not present a barrier to the ontological framework that is proposed in this paper. Indeed, concepts can be lifted from these disciplines and applied to research in SES with potentially positive research implications. For example, the concept of "event," borrowed from process philosophy, has the potential to bridge the dichotomy between nature and society that is embedded in so many theories, concepts, and disciplines (Debaise 2017). The concept of the event can also profitably be explored from different disciplinary perspectives, all of which can contribute to defining "event,"

\section{CONCLUSION: THE NEED FOR A PARADIGM SHIFT}

For the past few decades, sustainability science has been attempting to address the challenges of social-ecological integration, complexity, scale, and inter- and transdisciplinary integration. Yet, our ability to understand social-ecological systems as complex adaptive systems, in which the social and the ecological are coconstituted, is still limited. This suggests that we may need to critically reflect on, and shift, the paradigm that we are using to study these systems; a shift that an increasing number of researchers are calling for (Audouin et al. 2013). Many current approaches remain tethered to the possibilities allowed for by the paradigm of modernity, which relies on fixed categories that separate the social and the ecological from each other. These approaches tend to reduce complex problems, and struggle to accommodate change as an integral part of the system.

Although the studies reviewed in Table 1 stress the importance of relations and processes when addressing the identified challenges that SES research faces, these studies do not seem to consider making relations and processes the entry point for addressing these challenges. Simply reversing the order, that is, starting with processes instead of entities, and (of critical importance) studying one integrated system as opposed to two isolated systems, may be key to changing the paradigm under which we currently conduct sustainability research. From this perspective, the existence of entities is conditional on the existence of processes.

One way in which to facilitate the needed paradigm shift is through changing our mental models (Kaaronen 2018). Changing mental models can be thought of in terms of triple-loop learning, which refers to a deep level of learning wherein the structural context and factors that determine the frame of reference are transformed (Tosey et al. 2012). The first step to transforming our mental models is to attempt to understand what underlies at least some of the challenges that we face. In doing so, we can begin to understand why these challenges are the challenges that they are in the first place, and so we can begin to transform our way of thinking. Kaaronen (2018) argues that underlying our current mental models is the tendency to think of our actions and the world in terms of "entities." Instead of continuing to endorse this substance ontology, we should rather think in terms of the processes in which we are engaged, and which engage us. On this view, our encounters with objects and entities can be redefined as events in processes. Such a redefinition of the nature of reality can help us to begin to address the challenges that we currently face in SES research.

Such a paradigm shift toward starting from processes instead of entities would change the way we conceptualize, study, and address sustainability problems. A problem such as climate change adaptation in small-scale fisheries would be reconceptualized as a network of processes, recognizing that the challenges of climate change are entangled with many other problems such as poverty and globalization. The purpose is to go 
beyond presenting independent (but connected) problems toward uncovering the social-ecological relations that underlie the network of problems. In the case of climate change adaptation, for example, this requires a better understanding of the practices and social-ecological relations that perpetuate inequality and unsustainable resource use as well as those that enable collective agency. Based on such understanding, new governance approaches can be devised. Those approaches would aim at managing relations between and among people and the natural system, instead of managing people and ecosystem elements separately. This perspective shifts the focus of a study toward the processes that different actors, including the researchers, engage in and are engaged by in a given moment and context. Knowledge of these processes needs to be coproduced using approaches and methods that can reveal evolving relations and processes as well as their intertwinedness. Such a change in understanding and approaching real-world problems may help us analyze SES and develop governance approaches for sustainability transformations in a way that does justice to the intertwined, complex, cross-scale, and dynamic nature of SES.

Responses to this article can be read online at: http://www.ecologyandsociety.org/issues/responses. php/11425

\section{Acknowledgments:}

This project has received funding from the European Research Council (ERC) under the European Union's Horizon 2020 research and innovation program (grant agreement No 682472 - MUSES). The authors would like to thank Jannie Hofmeyr for his input during a workshop at the Centre for Complex Systems in Transition, that planted the first seed for this paper. RP acknowledges support by the Guidance for Resilience in the Anthropocene: Investments for Development (GRAID) project funded by the Swedish International Development Agency (Sida) hosted at Stockholm Resilience Centre.

\section{Data Availability Statement:}

Datalcode sharing is not applicable to this article as no new datal code were created or analyzed in this study.

\section{LITERATURE CITED}

Alonso Roldán, V., S. Villasante, and L. Outeiro. 2015. Linking marine and terrestrial ecosystem services through governance social networks analysis in Central Patagonia (Argentina). Ecosystem Services 16:390-402. https://doi.org/10.1016/j. ecoser.2015.02.010

Arthur, W. B. 2009. The nature of technology: what it is and how it evolves. Free Press, New York, New York, USA.

Arthur, W. B. 2015. Complexity and the economy. Oxford University Press, Oxford, UK.

Audouin, M., R. Preiser, S. Nienaber, L. Downsborough, J. Lanz, and S. Mavengahama. 2013. Exploring the implications of critical complexity for the study of social-ecological systems. Ecology and Society 18(3):12. https://doi.org/10.5751/ES-05434-180312
Bai, X., S. van der Leeuw, K. O'Brien, F. Berkhout, F. Biermann, E. S. Brondizio, C. Cudennec, J. Dearing, A. Duraiappah, M. Glaser, A. Revkin, W. Steffen, and J. Syvitski. 2016. Plausible and desirable futures in the Anthropocene: a new research agenda. Global Environmental Change 39:351-362. https://doi.org/10.1016/ j.gloenvcha.2015.09.017

Bodin, Ö., S. M. Alexander, J. Baggio, M. L. Barnes, R. Berardo, G. S. Cumming, L. E. Dee, A. P. Fischer, M. Fischer, M. Mancilla García, A. M. Guerrero, J. Hileman, K. Ingold, P. Matous, T. H. Morrison, D. Nohrstedt, J. Pittman, G. Robins, and J. S. Sayles. 2019. Improving network approaches to the study of complex social-ecological interdependencies. Nature Sustainability 2:551-559. https://doi.org/10.1038/s41893-019-0308-0

Cilliers, P. 2008. Complexity theory as a general framework for sustainability science. Pages 39-57 in M. Burns and A. Weaver, editors. Exploring sustainability science. A Southern African perspective. African SUN MeDIA, Stellenbosch, Southern Africa.

Cooke, B., S. West, and W. J. Boonstra. 2016. Dwelling in the biosphere: exploring an embodied human-environment connection in resilience thinking. Sustainability Science 11:831-843. https://doi.org/10.1007/s11625-016-0367-3

Debaise, D. 2017. Nature as event. The lure of the possible. Duke University Press, Durham, North Carolina, USA. https://doi. org/10.1215/9780822372424

DeLanda, M. 2006. A new philosophy of society: assemblage theory and social complexity. Bloomsbury, New York, New York, USA. https://doi.org/10.5040/9781350096769

Duvernoy, R. J. 2016. "Pure experience" and "planes of immanence": from James to Deleuze. Journal of Speculative Philosophy 30(4):427-451. https://doi.org/10.5325/jspecphil.30.4.0427

Eigenbrode, S. D., M. O'Rourke, J. D. Wulfhorst, D. M. Althoff, C. S. Goldberg, K. Merrill, W. Morse, M. Nielsen-Pincus, J. Stephens, L. Winowiecki, and N. A. Bosque-Pérez. 2007. Employing philosophical dialogue in collaborative science. BioScience 57(1):55-64. https://doi.org/10.1641/B570109

Fischer, J., T. A. Gardner, E. M. Bennett, P. Balvanera, R. Biggs, S. Carpenter, T. Daw, C. Folke, R. Hill, T. P. Hughes, T. Luthe, M. Maass, M. Meacham, A. V. Norström, G. Peterson, C. Queiroz, R. Seppelt, M. Spierenburg, and J. Tenhunen. 2015. Advancing sustainability through mainstreaming a socialecological systems perspective. Current Opinion in Environmental Sustainability 14:144-149. https://doi.org/10.1016/j.cosust.2015.06.002

Folke, C., L. Pritchard, F. Berkes, J. Colding, and U. Svedin. 2007. The problem of fit between ecosystems and institutions: ten years later. Ecology and Society 12(1):30. https://doi.org/10.5751/ ES-02064-120130

Garud, R., B. Simpson, A. Langley, and H. Tsoukas, editors. 2015. The emergence of novelty in organizations. Oxford University Press, Oxford, UK. https://doi.org/10.1093/acprof: oso/9780198728313.001.0001

Giusti, M. 2018. Home for future earth lovers: foundations of nature-connecting habitats for children. Dissertation. Stockholm Resilience Centre, Stockholm University, Stockholm, Sweden. 
Guerrero, A. M., N. J. Bennett, K. A. Wilson, N. Carter, D. Gill, M. Mills, C. D. Ives, M. J. Selinske, C. Larrosa, S. Bekessy, F. A. Januchowski-Hartley, H. Travers, C. A. Wyborn, and A. Nuno. 2018. Achieving the promise of integration in social-ecological research: a review and prospectus. Ecology and Society 23(3):38. https://doi.org/10.5751/es-10232-230338

Guerrero, A. M., Ö. Bodin, R. R. J. McAllister, and K. A. Wilson. 2015. Achieving social-ecological fit through bottom-up collaborative governance: an empirical investigation. Ecology and Society 20(4):41. https://doi.org/10.5751/ES-08035-200441

Hertz, T., and M. Schlüter. 2015. The SES-Framework as boundary object to address theory orientation in social-ecological system research: the SES-TheOr approach. Ecological Economics 116:12-24. https://doi.org/10.1016/j.ecolecon.2015.03.022

Ivakhiv, A. 2018. Contemporary process-relational thought: a primer. Pages 147-148 in A. Ivakhiv. Shadowing the Anthropocene: eco-realism for turbulent times. Punctum Books, Goleta, California, USA.

Kaaronen, R. O. 2018. Reframing tacit human-nature relations: an inquiry into process philosophy and the philosophy of Michael Polanyi. Environmental Values 27(2):179-201. https://doi. org/10.3197/096327118X15162907484466

Kramer, D. B., J. Hartter, A. E. Boag, M. Jain, K. Stevens, K. A. Nicholas, W. J. McConnell, and J. Liu. 2017. Top 40 questions in coupled human and natural systems (CHANS) research. Ecology and Society 22(2):44. https://doi.org/10.5751/es-09429-220244

Lebel, L., E. Nikitina, C. Pahl-Wostl, and C. Knieper. 2013. Institutional fit and river basin governance: a new approach using multiple composite measures. Ecology and Society 18(1):1. https:// doi.org/10.5751/ES-05097-180101

Lélé, S. M. 1991. Sustainable development: a critical review. World Development 19(6):607-621. https://doi.org/10.1016/0305-750x (91) $90197-\mathrm{p}$

Levin, S., T. Xepapadeas, A.-S. Crépin, J. Norberg, A. de Zeeuw, C. Folke, T. Hughes, K. Arrow, S. Barrett, G. Daily, P. Ehrlich, N. Kautsky, K.-G. Mäler, S. Polasky, M. Troell, J. R. Vincent, and B. Walker. 2013. Social-ecological systems as complex adaptive systems: modeling and policy implications. Environment and Development Economics 18(2):111-132. https://doi.org/10.1017/ $\underline{\mathrm{S} 1355770 \mathrm{X} 12000460}$

Lindkvist, E., X. Basurto, and M. Schlüter. 2017. Micro-level explanations for emergent patterns of self-governance arrangements in small-scale fisheries - a modeling approach. PLoS ONE 12(6):e0179439. https://doi.org/10.1371/journal. pone. 0175532

Liu, J., T. Dietz, S. R. Carpenter, M. Alberti, C. Folke, E. Moran, A. N. Pell, P. Deadman, T. Kratz, J. Lubchenco, E. Ostrom, Z. Ouyang, W. Provencher, C. L. Redman, S. H. Schneider, and W. W. Taylor. 2007. Complexity of coupled human and natural systems. Science 317:1513-1516. https://doi.org/10.1126/science.1144004

Liu, J., V. Hull, M. Batistella, R. DeFries, T. Dietz, F. Fu, T. W. Hertel, R. C. Izaurralde, E. F. Lambin, S. Li, L. A. Martinelli, W. J. McConnell, E. F. Moran, R. Naylor, Z. Ouyang, K. R. Polenske, A. Reenberg, G. de Miranda Rocha, C. S. Simmons, P. H. Verburg,
P. M. Vitousek, F. Zhang, and C. Zhu. 2013. Framing sustainability in a telecoupled world. Ecology and Society 18 (2):26. https://doi.org/10.5751/ES-05873-180226

Marston, S. A., J. P. Jones III, and K. Woodward. 2005. Human geography without scale. Transactions of the Institute of British Geographers 30(4):416-432. https://doi.org/10.1111/ j.1475-5661.2005.00180.X

Martín-López, B., M. R. Felipe-Lucia, E. M. Bennett, A. Norström, G. Peterson, T. Plieninger, C. C. Hicks, F. Turkelboom, M. García-Llorente, S. Jacobs, S. Lavorel, and B. Locatelli. 2019. A novel telecoupling framework to assess social relations across spatial scales for ecosystem services research. Journal of Environmental Management 241:251-263. https://doi.org/10.1016/ j.jenvman.2019.04.029

May, T. 2005. Gilles Deleuze: a general introduction. Cambridge University Press, Cambridge, UK.

Mesle, C. R. 2008. Experience all the way down: seeking an imaginative leap. Pages 31-41 in C. R. Mesle. Process-relational philosophy: an introduction to Alfred North Whitehead. Templeton Press, West Conshohocken, Pennsylvania, USA.

Muradian, R., and U. Pascual. 2018. A typology of elementary forms of human-nature relations: a contribution to the valuation debate. Current Opinion in Environmental Sustainability 35:8-14. https://doi.org/10.1016/j.cosust.2018.10.014

Nicholson, D. J., and J. Dupré. 2018. Everything flows: towards a processual philosophy of biology. Oxford University Press, Oxford, UK.

Norgaard, R. B. 2002. Optimists, pessimists, and science. BioScience 52(3):287-292. https://doi.org/10.1641/0006-3568 (2002)052[0287:OPAS]2.0.CO;2

Olsson, P., and C. Folke. 2001. Local ecological knowledge and institutional dynamics for ecosystem management: a study of Lake Racken Watershed, Sweden. Ecosystems 4:85-104. https:// doi.org/10.1007/s100210000061

Peter, C., and M. Swilling. 2014. Linking complexity and sustainability theories: implications for modeling sustainability transitions. Sustainability 6:1594-1622. https://doi.org/10.3390/ $\underline{\text { su6031594 }}$

Poli, R. 2010. An introduction to the ontology of anticipation. Futures 42:769-776. https://doi.org/10.1016/j.futures.2010.04.028

Preiser, R., R. Biggs, A. De Vos, and C. Folke. 2018. Socialecological systems as complex adaptive systems: organizing principles for advancing research methods and approaches. Ecology and Society 23(4):46. https://doi.org/10.5751/ES-10558-230446

Rajagopalan, R., and G. Midgley. 2015. Knowing differently in systemic intervention. Systems Research and Behavioral Science 32:546-561. https://doi.org/10.1002/sres.2352

Rogers, K. H., R. Luton, H. Biggs, R. Biggs, S. Blignaut, A. G. Choles, C. G. Palmer, and P. Tangwe. 2013. Fostering complexity thinking in action research for change in social-ecological systems. Ecology and Society 18(2):31. https://doi.org/10.5751/es-05330-180231

Santos, G. C. 2015. Ontological emergence: How is that possible? Towards a new relational ontology. Foundations of Science 20 (4):429-446. https://doi.org/10.1007/s10699-015-9419-X 
Schlüter, M., L. J. Haider, S. J. Lade, E. Lindkvist, R. Martin, K. Orach, N. Wijermans, and C. Folke. 2019. Capturing emergent phenomena in social-ecological systems: an analytical framework. Ecology and Society 24(3):11. https://doi. org/10.5751/ES-11012-240311

Schoon, M., and S. van der Leeuw. 2015. The shift toward socialecological systems perspectives: insights into the human-nature relationship. Natures Sciences Sociétés 23(2):166-174. https://doi. org/10.1051/nss/2015034

Stark, H. 2017. Deleuze, subjectivity and nonhuman becomings in the Anthropocene. Dialogues in Human Geography 7 (2):151-155. https://doi.org/10.1177/2043820617717857

Steinberg, P., and K. Peters. 2015. Wet ontologies, fluid spaces: giving depth to volume through oceanic thinking. Environment and Planning D: Society and Space 33(2):247-264. https://doi. org/10.1068/d14148p

Stone-Jovicich, S. 2015. Probing the interfaces between the social sciences and social-ecological resilience: insights from integrative and hybrid perspectives in the social sciences. Ecology and Society 20(2):25. https://doi.org/10.5751/ES-07347-200225

Swyngedouw, E. 2004. Scaled geographies: nature, place, and the politics of scale. Pages 129-153 in E. Sheppard and R. B. McMaster, editors. Scale and geographic inquiry: nature, society, and method. Blackwell, Oxford, UK. https://doi. org/10.1002/9780470999141.ch7

Tosey, P., M. Visser, and M. N. K. Saunders. 2012. The origins and conceptualizations of 'triple-loop' learning: a critical review. Management Learning 43(3):291-307. https://doi. org/10.1177/1350507611426239

Turner II, B. L., K. J. Esler, P. Bridgewater, J. Tewksbury, N. Sitas, B. Abrahams, F. S. Chapin III, R. R. Chowdhury, P. Christie, S. Diaz, P. Firth, C. N. Knapp, J. Kramer, R. Leemans, M. Palmer, D. Pietri, J. Pittman, J. Sarukhán, R. Shackleton, R. Seidler, B. van Wilgen, and H. Mooney. 2016. Socio-environmental systems (SES) research: What have we learned and how can we use this information in future research programs. Current Opinion in Environmental Sustainability 19:160-168. https://doi.org/10.1016/ j.cosust.2016.04.001

Waring, T. M. 2010. New evolutionary foundations: theoretical requirements for a science of sustainability. Ecological Economics 69(4):718-730. https://doi.org/10.1016/j.ecolecon.2008.10.017

Waring, T. M., M. A. Kline, J. S. Brooks, S. H. Goff, J. Gowdy, M. A. Janssen, P. E. Smaldino, and J. Jacquet. 2015. A multilevel evolutionary framework for sustainability analysis. Ecology and Society 20(2):34. https://doi.org/10.5751/ES-07634-200234

Weinbaum, D. R. 2015. Complexity and the philosophy of becoming. Foundations of Science 20:283-322. https://doi. org/10.1007/s10699-014-9370-2

Wells, J. L. 2013. Complexity and sustainability. Routledge, New York, New York, USA.

West, S. 2016. Meaning and action in sustainability science: interpretive approaches for social-ecological systems research.
Dissertation. Stockholm Resilience Centre, Stockholm University, Stockholm, Sweden.

West, S., L. J. Haider, V. A. Masterson, J. P. Enqvist, U. Svedin, and M. Tengö. 2018. Stewardship, care and relational values. Current Opinion in Environmental Sustainability 35:30-38. https:// doi.org/10.1016/j.cosust.2018.10.008 